\title{
Vaccines: Specific Features, Simulation of Impact and Medico-Economic Modelling
}

\author{
Odile Launay ${ }^{1}$, Didier Hoch ${ }^{2}$, Christelle Saint-Sardos ${ }^{2}$, Didier Guillemot ${ }^{3}$ and the participants of Round Table \\ $n^{\circ} 6$ of Giens $X X V^{\star}$ \\ 1 Université Paris Descartes, AP-HP, Inserm, CIC de Vaccinologie Cochin Pasteur, Paris, France \\ 2 Sanofi Pasteur MSD, Lyon, France \\ 3 Unité de Pharmacoépidémiologie et Maladies Infectieuses Institut Pasteur/Inserm U 657, Paris, France \\ Text received 26 april 2010; accepted 15 june 2010
}

Keywords:
vaccine;
vaccinology;
clinical research;
translational research;
clinical centre of
investigation;
network;
epidemiology;
medico-economic
modelling

\begin{abstract}
In a context where a number of vaccinations have recently been recommended in France, and where a large number of vaccines are under development, the Round Table has reviewed the specific features of vaccines in France, namely clinical development, medico-economic modelling, evaluation and communication. In each of these domains, the key stages and processes to be improved have been identified, and proposals made. The main strategic challenges are to promote the development of vaccines in France by access to the large-scale monitoring of populations, to look ahead and coordinate the evaluation of vaccines by the various parties involved, to widen communication about vaccination strategies, in order to improve the perception of vaccines and the acceptability of vaccinations, and to increase vaccination coverage. The Round Table has also proposed the creation of a working group to be responsible for pursuing, monitoring and implementing the proposals formulated.
\end{abstract}

\section{Introduction}

Round Table no. 6 "Vaccines: specific features, simulation of impact and medico-economic modelling" fits in the context:

- Of the recent recommendation of a number of vaccines in France: vaccines against infections with human papillomavirus, ${ }^{[1,2]}$ conjugate pneumococcus, ${ }^{[3]}$ and conjugate meningococcus. ${ }^{[4]}$

- And of the current development of numerous new vaccines: some one hundred vaccines are currently being developed including vaccines against infections from: staphylococcus aureus, meningococcus $B$, chlamydia, dengue fever, herpes, HIV, hepatitis $\mathrm{C}$, malaria. ${ }^{[5]}$

In France as in the rest of the world, vaccination is still one of the best tools for the prevention of serious infectious diseases. Furthermore, vaccines constitute a therapeutic area of excellence in France: the public health, political and industrial benefit of this excellence justifies the French attractiveness being maintained.

\footnotetext{
^ For the list of participants, see end of article.
}

The objective of the Round Table was to review the specific features of vaccines by identifying the key stages and processes in improving vaccines throughout a lifetime, and to propose an action plan.

The Round Table's work was organised around presentations which prompted discussion and debate: "The specific features of vaccines" (D. Hoch), "The specific features of the development of vaccines, selection criteria for the implementation of licensing trials" (B. Fritzell), "Vaccination and epidemiological impact" (P.-Y. Boelle), "Cost-effectiveness modelling” (B. Dervaux), "Place of models in vaccination recommendations" (D. LévyBruhl), "Safety, specific features of vaccines" (J.-P. Fagot), "Perception of and communication about vaccines" (D. Floret), "From the Marketing Authorization to vaccination" (C. Saint Sardos). Debate was confined to preventive vaccination.

This review has allowed the four main areas of specific features of vaccines to be identified, namely clinical development, medico-economic modelling, evaluation in terms of public health and recommendations, and communication. 


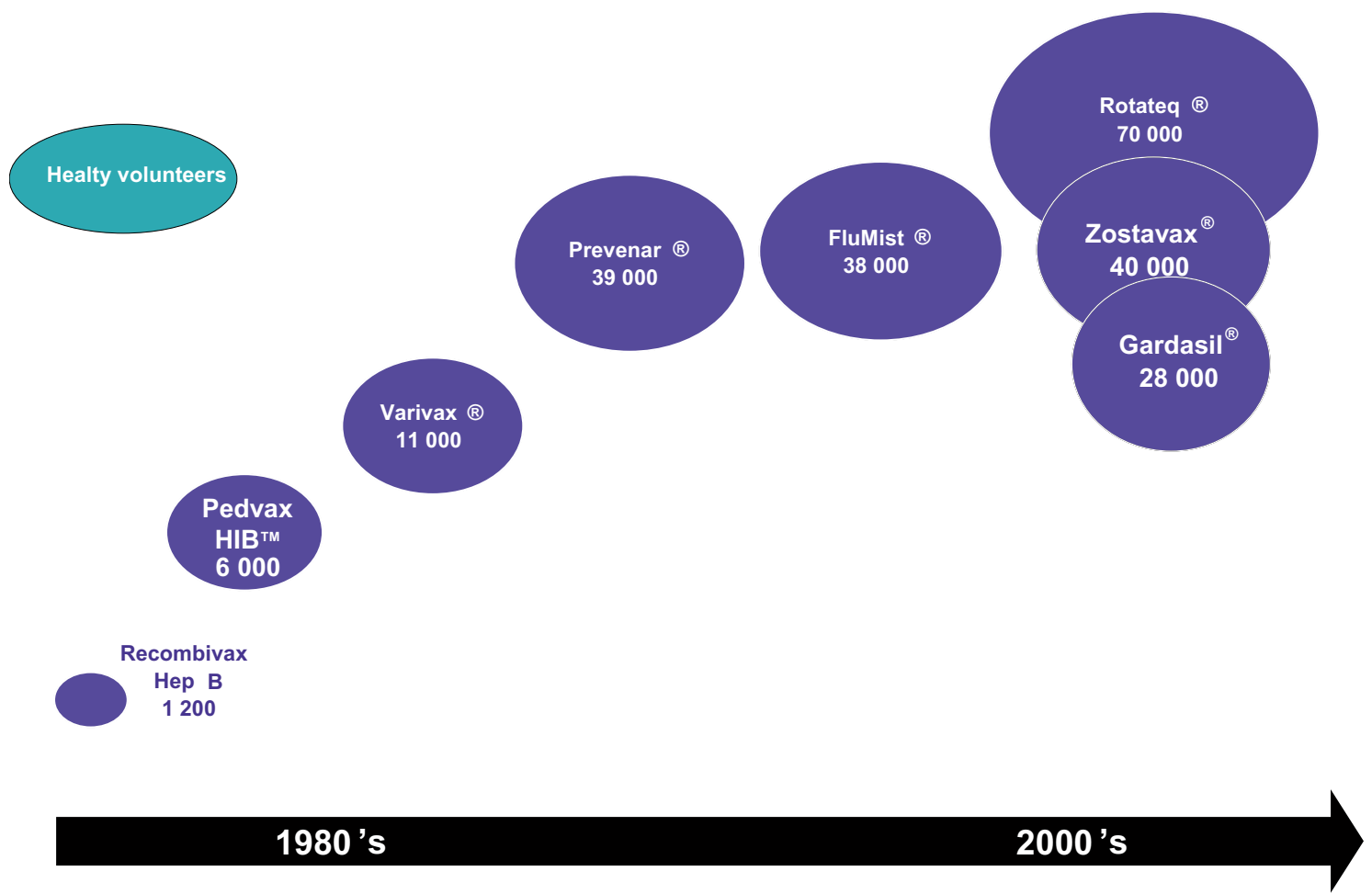

Fig. 1. Number of subjects enrolled in phase III vaccination-development clinical studies.

\section{Specific features of vaccines in terms of clinical development and monitoring}

\section{1. Review}

Vaccines are one of the rare medicinal public health tools used for primary prevention, and are administered to "healthy" individuals to reduce the risk of the occurrence of infectious diseases in general, and not to sick people or people presenting risk factors, in contrast to so-called "classic" drugs. By their nature, the target populations are generally very broad populations defined on the basis of demographic criteria (for example babies or people over 65 years old). ${ }^{[6]}$

In the $21^{\text {st }}$ century, one of the major particularities of vaccines relates to the diseases for which vaccines are intended to reduce the risk. They are serious diseases (meningitis, septicaemia, etc.) which threaten the vital prognosis of the people affected. They are also often diseases with a fairly modest incidence level. Thus, efficacy (and the first base of the safety argument) needs to be demonstrated via clinical trials on a very large number of people (30000 to 70000 subjects) [figure 1]. ${ }^{\text {[7-9] }}$

Another important particularity relates to the risks of sideeffects of vaccines. Indeed, the anticipated collective benefit of a vaccine is generally superior to the sum of the benefit for each of the individuals vaccinated. In this sense, deciding that a new vaccine brought onto the market be accompanied by a vaccination programme engages more the responsibility of public-health decision-makers than the medical decision-makers who prescribe the actual vaccination. There is thus, for a vaccine more than for any other drug, a "political" need to anticipate and react to the risk of the occurrence of side-effects, this imperative being reinforced by the potential impact of an approximate management of sideeffects of vaccines which can lead to a failure of the vaccination policy and consequently to a loss of opportunity with regard to the infectious disease concerned even for people who have not been vaccinated. This has been observed in the past. Naturally, as with any other drug, in addition to the classic pharmaco-vigilance, Risk Management Plans (both European and French) ${ }^{[7,10]}$ and postlicensing studies required in the context of the registration for reimbursement ${ }^{[11]}$ are important to monitor the tolerance of vaccines and their public health benefit (impact in terms of morbidity, mortality, health care required, epidemiology and microbial ecology).

We are forced to note that in France there are no means to carry out investigations on the scale necessary for the development or monitoring of certain vaccines. This work is carried out in particular in the United States, where certain health-care organisations have sophisticated information systems, as is the case with Kaiser Permanente (Health Maintenance Organization), ${ }^{[12]}$ or the Department of Veterans Affairs (public institution). ${ }^{[13]}$ Some 
European countries (Denmark, Sweden, Norway, the Netherlands... . ${ }^{[14]}$ also have registers, large-scale information collection systems or platforms allowing trials on vaccines to be conducted.

In 2008, a French clinical network dedicated to vaccinology (REIVAC), was created to promote clinical research in vaccinology. REIVAC's missions are to improve attractivness of France for implementation of preventive and therapeutic vaccine trilas from pre-clinical to clinical phases I to III and to link up scientists and physicians, as well as industries and academic institutions, in order to develop exploratory research. REIVAC is sponsored by the Group of Public Interest from the National Management Trial Center for Health Products (GIP CeNGEPS) and the National Institute of Health and Medical Research (Inserm).

\subsection{Objective and proposals of the Round Table}

\subsubsection{Objective}

As vaccines are potentially a "therapeutic" area of excellence for France, the Round Table identified the need to be able to develop, in France, a platform allowing phase III trials and phase IV investigations to be conducted. This requires access to large-scale defined population monitoring (cohorts).

\subsubsection{Proposals}

- Networking and interlinking of academic vaccinology experts, comprising in particular epidemiologists, virobacteriologists, immunologists, clinicians, methodologists and sociologists with the support of REIVAC network.

- Constitution of a database with a view to building a preexisting information system essential for phase III trials, observational studies or Risk Management Plans for vaccines.

The General Practice Research Database (GPRD database, United Kingdom) is an example of a "patient" database which France could obtain for itself. ${ }^{[15]}$

Various health management and organisation bodies in France have databases specific to their area of activity. This is the case in particular with the "Caisse Nationale d'Assurance Maladie" (National Health Insurance Fund, french acronym: CNAM), which via its management system and its statistics bases has information about healthcare for all its insured. ${ }^{[16]}$ Likewise, the "Agence Technique de l'Information sur l'Hospitalisation" [Technical Hospitalisation Information Agency manages the "Programme de Médicalisation des Systèmes d'Information Hospitaliers" (Hospital Information Systems Medicalisation Programme, french acronym: PMSI)], an information system with records the pathologies and care of patients treated in (public and private) healthcare establishments in France. ${ }^{[17]}$ We would also cite the information collected by the 31 regional pharmaco-vigilance centres. The networking of the existing databases in France, and their opening for research and clinical development purposes, could form a platform of choice allowing the clinical development and the monitoring of new vaccines in France.

\section{- Constitution of shared data about behaviours, allowing ac- cess to data of the type "number of contact subjects" or vaccination coverage.}

The evaluation of new vaccination strategies requires the modelling of the anticipated epidemiological impact of new vaccinations. This modelling work requires access to contact matrices, reflecting the probabilities of contaminating contacts between subjects. To be relevant, these matrices need to be geared to specific French features, including for example the age at which children enter collective establishments, the nature of the collective establishments for children based on age, the various types of establishment, etc. As the models are very sensitive to the choice of contact matrices ${ }^{[18]}$, the constitution of shared data about behaviours (number of contact subjects, vaccination coverage) is a preliminary to a quality evaluation of new vaccinations.

\section{- Creation of a "Très Grande Infrastructure de Recherche épidémiologique" (Very Large Epidemiological Research Infrastructure, french acronym: TGIR).}

TGIRs are tools created with a view to conducting major research and which can have a service role for one or more largescale scientific communities. TGIRs differ greatly depending on their purpose, their budget, and the scale of their community of users. The area of biology and health form the subject of existing, confirmed or planned TGIRs (Clinical Investigation Centres, Large-scale Biomedical Cohort Research and Development Platform ....). ${ }^{[19]}$

Epidemiology allows populations and diseases to be observed, as well as hypotheses about determinants of health's states and the development of infections and pathologies to be generated. It thus constitutes the basis for fundamental research on any new vaccine. It is also an essential clarification element for decision-making on the topic of vaccination. So, given the importance of epidemiological research, and the multiplicity of interested scientific communities, a TGIR in epidemiological research would be totally sensible.

- Development of translational research centres, to rival the structures available in other countries and ensure visibility of France in the field of vaccine development. 


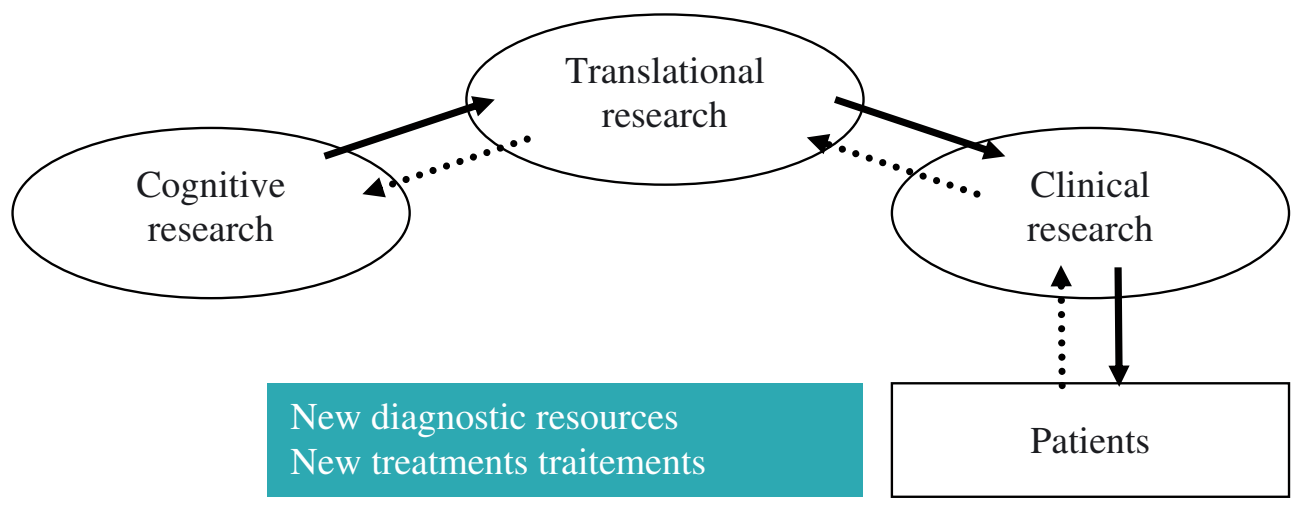

Fig. 2. Translational research: from patient to patient. ${ }^{[20]}$

The purpose of translational research is to pursue the research-care continuum and the fastest possible application of discoveries for the benefit of patients. The translational stage, which starts with the identification of targets or candidate products and ends with proof of the clinical concept, corresponds to a range of know-how and requires a professionalised infrastructure providing a set of services for communities of researchers (figure 2).

Translational research, also called experimental medicine, was created over 20 years ago in the United States. In France, the Clinical Centers of Investigation (CICs), are public structures dedicated to translational research, located in Universitary hospitals. The CIC Cochin Pasteur, located in Cochin Hospital is the single CIC dedicated to vaccinology.

In France, the 2003-2007 Cancer Plan positioned Translational Research at the heart of its research programme, under the coordination of cancer centres with numerous public/private partnerships. Translational research is also applied in other areas (Alzheimer's disease, TGIR translational research project in the area of neurological diseases / rare diseases).

The development of translational research centres specialising in the prevention of infectious diseases would without doubt form a favourable environment for the advent of new vaccines developed in France.

\section{Specific features in terms of the use of models for the definition of new vaccination strategies}

\subsection{Review}

The approach and the definition of new vaccination strategies is based in particular on the modelling of the expected epidemiological and economic impacts of the introduction of vaccination. ${ }^{[20]}$ This approach is taken under the aegis of the "Comité technique des vaccinations" (Technical Vaccination Committee, french acronym: CTV), and involves various partners, including the "Institut National de Veille Sanitaire" (National Health Monitoring Institute, french acronym: InVS). ${ }^{[21]}$

The models developed can be highly complex (from static to dynamic) and take into account:

- The natural history of the targeted disease, the epidemiology of the infection, the current management of the disease, and the existing means of prevention.

- The expected impact of the vaccines (benefits, risks) on the infectious agents and their evolution, for those vaccinated (individual benefit), for those not vaccinated (collective impact associated with population immunity), for health insurance, for society (productivity, work days lost).

In this context, the provision of databases about diagnoses and care, and also about behaviours - as previously described (2.2.2) - would provide access to good-quality French epidemiology and economic data in order to "feed" the models with the most relevant data.

The inherent complexity of the models to be developed in order to assess the expected impact of the vaccine, and in order to collect some of the data needed for analyses, can result in delays being generated in the opinions of the CTV.

The CTV's procedure for processing vaccine dossiers (February 2010) states furthermore: "The CTV's draft opinion is provided as far as possible within a period of 3 months from the positive opinion of the European Drugs Agency or at the end of the mutual recognition procedure or the national procedure. Where additional data have been requested from the laboratory, or where additional studies are necessary, in particular a mathematical model or a medico-economic evaluation, this period may be extended depending on the time needed to mobilise resources and the complexity of the work." 


\subsection{Proposal}

The Round Table has identified:

- The need to move forward as soon as possible with the preparation of the model(s) and the collection of data needed to evaluate new vaccination strategies, in parallel with the European regulatory evaluation, so that the time until the population has access to the new vaccines are not lengthened excessively by the modelling procedure.

- The need to formalise the interactions between agencies, research and industrial operators in the development of models.

\section{Specific features in terms of evaluation and access to the reimbursement of new vaccines}

\section{1. Review}

The route taken by vaccines to achieve reimbursement is marked by the double nature of the vaccine, which is both a drug and a public health tool. The vaccine is thus subject to a distinct regulatory process.

\subsubsection{A route characterised by an additional stage}

As a drug, a new vaccine classically forms the subject of an opinion by the "Commission de la Transparence de la Haute Autorité en Santé" (Transparency Commission of the High Health Authority, french acronym: HAS), which evaluates the "Service Médical Rendu" (Actual Benefit, french acronym: SMR) and the "Amélioration du Service Médical Rendu" (Improvement in Actual Benefit, french acronym: ASMR), and a decision of the "Comité Économique des Produits de Santé" (Economic Committee for Health Product, french acronym: CEPS) which fixes the price of it.

But its concomitant nature of an instrument of public health means that it is also evaluated by a third authority, the Technical Vaccination Committee (CTV). This is a permanent technical committee composed of experts in vaccination matters and attached to the "Haut Conseil de la Santé Publique" (High Council of Public Health, french acronym: HCSP), the consultative body to the Minister of Health, to contribute to the definition, evaluation and consideration of the public health policy in France. Finally, the vaccination policy is drawn up directly by the minister of health ${ }^{[22]}$ who sets the immunisation conditions, states the necessary recommendations and publishes the vaccination calendar following the opinion of the HCSP.
The role of the CTV is: ${ }^{[20]}$

- To provide the scientific monitoring of developments and perspectives in the field of vaccines.

- To produce the vaccination strategy on the basis of epidemiological data, individual and collective benefit-risk studies and medico-economic studies relating to the measures under consideration.

- To propose adaptations in terms of vaccination recommendations and obligations to update the vaccination calendar (figure 3).

\subsubsection{A route characterised by a double economic evaluation}

In France, the medico-economic evaluation of drugs by the High Health Authority is carried out principally after reimbursement, during the periodic re-evaluation of therapeutic classes, or during the evaluation of treatment strategies. ${ }^{\text {[24] }}$

With regard to vaccines, the Round Table participants were agreed that these substances are an exception to the rule of absence of medico-economic evaluation at initial reimbursement applied to other drugs, given the importance of this subject in determining the vaccination strategy.

The medico-economic aspect should thus be part of the evaluation performed by the CTV prior to reimbursement, at the recommendation stage. ${ }^{[20]}$ Then, the economic issues are tackled again by the CEPS, when the price is set.

The result is that two actors - the CTV and the CEPS - carry out an economic evaluation on the same vaccine, and this review raises the question of their coordination, in particular with regard to the price of vaccines, if the CTV carries out medico-economic analyses on the basis of price hypotheses or hypotheses of reimbursement conditions which have not yet been evaluated by the CEPS.

The following emerged over the course of the Round Table's discussions:

- A lack of clarity about the roles of each actors, insufficient communication and coordination.

- The need to specify where and when the medico-economic evaluation is carried out, and for which decision-maker(s).

\subsection{Objective and proposals}

\subsubsection{Objective}

To anticipate and coordinate the evaluation of new vaccines in France. 


\section{France - General description of Recommendation \& Funding process for vaccines}

\begin{tabular}{|c|c|c|c|c|c|c|}
\hline $\begin{array}{c}\text { EMEA } \\
\text { Afssaps }\end{array}$ & $\begin{array}{l}\text { HCSP } \\
\text { CTV }\end{array}$ & $\begin{array}{c}\text { HAS } \\
\text { CT }\end{array}$ & CEPS & $\begin{array}{l}\text { Ministry of } \\
\text { Health }\end{array}$ & $\begin{array}{l}\text { Population } \\
\text { Access to } \\
\text { the } \\
\text { vaccine }\end{array}$ & $\begin{array}{c}\text { Post } \\
\text { Marketing } \\
\text { Surveillance }\end{array}$ \\
\hline $\begin{array}{l}\text { Marketing } \\
\text { Authorisation } \\
\text { Indications }\end{array}$ & $\begin{array}{c}\text { Advise for vaccine } \\
\text { "Recommendations 》 } \\
=\text { National Vaccination } \\
\text { Calendar }\end{array}$ & $\begin{array}{l}\text { Evaluation of } \\
\text { (relative) medical } \\
\text { added value } \\
\text { SMR \& ASMR }\end{array}$ & $\begin{array}{c}\text { Price \& } \\
\text { Reimbursement } \\
\text { conditions } \\
\text { Post Marketing } \\
\text { surveillance }\end{array}$ & $\begin{array}{l}\text { Publication } \\
\text { in the Official } \\
\text { Journal (JO) }\end{array}$ & & $\begin{array}{l}\text { Vaccination } \\
\text { Impact on } \\
\text { Public Health }\end{array}$ \\
\hline
\end{tabular}

Fig. 3. Vaccines: the route to reimbursement.

\subsubsection{Proposals}

- Establishment of an identified network of experts for the "Evaluation of vaccination strategies", including in particular vaccinologists, economists and modelling specialists.

- Development of a stronger interface between the authorities which evaluate vaccination strategies and vaccines (Afssaps/CTV/HCSP/HAS/CEPS), with in particular:

- agreement by all the authorities on their respective missions regarding vaccines and vaccination,

- clarification of the entire process taking the vaccine from marketing authorisation through to reimbursement,

o the creation of a temporary liaison committee between the various authorities involved in the evaluation of the vaccine.

- Improvement of the interface between the authorities evaluating vaccination strategies/vaccines and, manufacturers, with the definition and communication of agreed operating procedures.

In this regard, the CTV's procedure for processing vaccine dossiers (February 2010) constitutes an initial stage in this process.

\section{Specific features of vaccines in terms of perception and communication}

\subsection{Review}

Vaccines are unique health assets:

- No technological progress (other than potable water) - including antibiotics - has had as much influence as vaccination on the reduction in mortality and the growth of the world's population. ${ }^{25]}$

- Of all medical techniques, this is probably the one which has been, and indeed still is, the subject of the most controversy (after the round table, the period of the A/H1N1 flu pandemic provided a striking demonstration of this).

\subsubsection{Declared perception of vaccination by the population and General Practitionists (GPs)}

Opinion polls show that around $90 \%$ of the population is in favour of vaccination, and less than $5 \%$ solid opponents.

Likewise, $97 \%$ of GPs say they are in favour of vaccination, with $75 \%$ very much in favour. ${ }^{[26]}$ It is to be noted that primary physicians carry out $90 \%$ of vaccinations in France, hence their major role in the information and perception of the population with regard to vaccines (figure 4). 
Positive opinions ("very positive" and "rather positive") to the vaccination, according to sex, among 15 to 75 years olds.

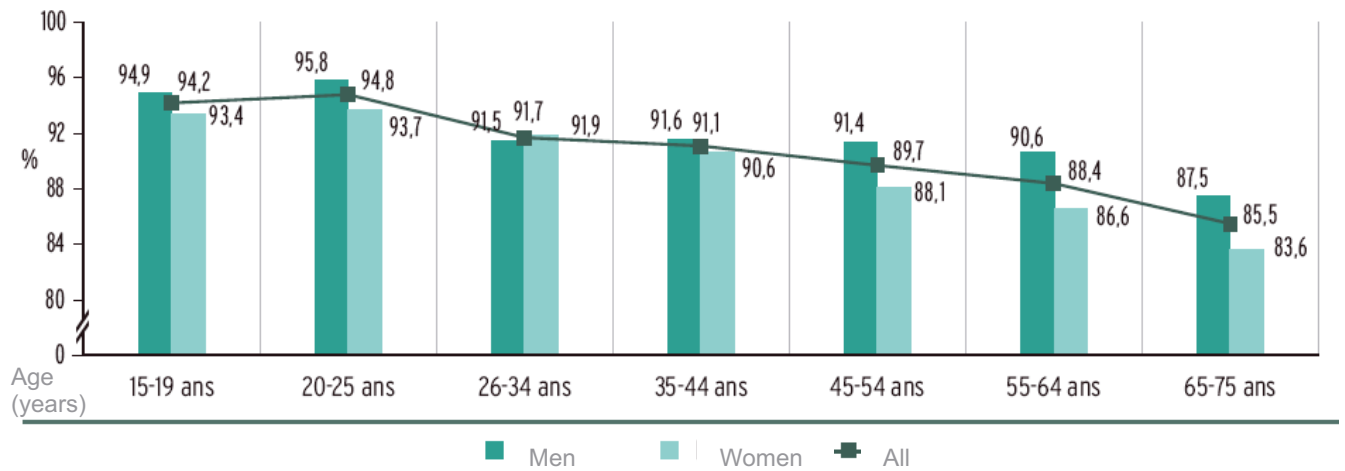

Fig. 4. General public's opinions with regard to vaccinations. ${ }^{[27]}$

\subsubsection{Reality of vaccination}

But the vaccination coverage levels in France are not as high as these optimistic figures. While vaccination coverage is satisfactory for vaccinations in childhood $(98 \%$ at 2 years old for pentavalent vaccinations), it decreases with age (80\% for the diphtheria-tetanus-poliomyelitis vaccination in year 9), and becomes problematic in the adult (after 65 years of age: cover at around $60 \%$ for tetanus, and $10 \%$ for diphtheria). This inadequate vaccination coverage has been reflected recently by the development of epidemic centres of measles. An extremely low coverage rate for hepatitis B vaccination in France is to be noted, as a result of controversy about its safety.

This reality reflects the existence in a section of the population and the medical community of scepticism about - or even opposition to - vaccination.

\subsubsection{Sceptics and opponents}

Vaccination sceptics do not reject all vaccinations, but tend to have a selective approach. They are also very demanding in terms of information about vaccination strategy, vaccination efficacy and vaccination safety.

Vaccination opponents (estimated at less than 5\% of the population) are a heterogeneous group with very diverse motivations: religious, philosophical or ideological beliefs; demanding respect of individual liberties; attracted by alternative medicine; belief in "Conspiracy Theories".

It is to be noted that, in this more or less solid opposition, the role of doctors is probably very important, as they are referral agents for the population in the matter of vaccination.
Generally, a growing need for information and explanation about vaccination is noted (gravity of the disease prevented, efficacy and safety of the vaccine) [table I].

\subsubsection{Need to improve communication regarding vaccination}

Generally, our time is characterised by a higher demand for information about all subjects: health, in particular vaccination, is no exception to this development. More than any other area of health, to be accepted, vaccinations need to be explained and understood.

This demand emanates from the population, but also GPs, who are the main actors of vaccination in France.

\subsection{Objectives and proposals of the Round Table}

- Inform the public and healthcare professionals

- Increase media coverage of the European Vaccination Week.

- Communicate the conclusions of the recommendations to the public and professionals, with for example the organisation of press conferences by the CTV/HCSP when important recommendations are issued.

- Development of an official internet site on vaccination intended for the general public.

- Annual communication by Afssaps on the Risk Management Plan data, intended for the public and health professionals.

\section{- Train health professionals}

○ "Institutionalise" the financing of Infovac. ${ }^{[30]}$

- Increase the training of health professionals in prevention and vaccination. 
Table I. "Anti-vaccination" arguments: what lessons can be drawn? What measures should be taken? What answers should be given?.

\begin{tabular}{ll}
\hline "Anti-vaccination" argument ${ }^{[28,29]}$ & Measure to be taken or answer to be given \\
\hline Vaccination=a violation of the rights of the individual & $\begin{array}{l}\text { Consider the vaccination obligations: the more coercive measures are imposed, } \\
\text { the more vaccination opponents are bolstered }\end{array}$ \\
Vaccination=the result of a conspiracy & $\begin{array}{l}\text { Need to reflect on the management of certain links between vaccinology experts } \\
\text { and industry (including attendances at conferences) }\end{array}$ \\
Vaccination=danger & $\begin{array}{l}\text { Anticipate any "relations in time" when introducing new vaccinations, with } \\
\text { communication geared towards doctors }\end{array}$ \\
& $\begin{array}{l}\text { - Demonstrate that the vaccine pharmaco-vigilance system is serious, and prob- } \\
\text { ably improve it } \\
\text { - Analyse the adverse effects reported (in particular in clinical trials) in terms of } \\
\text { accountability } \\
\text { - Answer the questions raised by doctors about vaccination }(e . g . \text { Infovac), and } \\
\text { help them to answer the population. For each new recommendation, produce a } \\
\text { simplified version sent for publication in journals read by doctors }\end{array}$ \\
\hline
\end{tabular}

\section{- Involve}

- Invite, as observers, representatives of the general population to CTV meetings (in the same way as the American body responsible for vaccination recommendations).

- Propose citizen debates on vaccination (e.g. on the topic: the vaccination obligation).

- Reflect on the place of industrialists / academics.

Another point addressed by the Round Table was that of the management of conflicts of interest of vaccinology experts: this subject may form the subject of a Round Table in 2010.

\section{Conclusion}

The Rencontres Nationales de Pharmacologie Clinique de Giens XXV (National Meeting on Clinical Pharmacology) provided Round Table $n^{\circ} 6$ with the opportunity to draw up a review of the specific features of vaccines, and to formulate a list of ambitious proposals.

Recent experience with vaccination against the pandemic A/H1N1 flu in France has shown that the development of effective and safe vaccines, coordination between actors in public health and communication about vaccination strategies are real public health challenges. The proposals formulated by the Round Table aim to improve the processes in this broad area specific to vaccines.

The Round Table proposes the creation of a working group to be responsible for pursuing, monitoring and implementing the proposals formulated.

Participants. Véronique Ameye (Laboratoire Novartis Pharma SAS), Nathalie Billon (Laboratoire Sanofi Aventis), Pierre-Yves Boelle (Université Pierre et Marie Curie, Paris), Jocelyn Courtois (Cnamts, Paris), Benoît Dervaux (DRCI, CHRU,
Lille), Isabelle Diaz (Leem-Ariis, Paris), Jean-Paul Fagot (Afssaps, Paris), Daniel Floret (Hôpital Femme Mère Enfant, Bron), Bernard Fritzell (Laboratoire Wyeth Pharmaceuticals), Anne-Françoise Gaudin (Laboratoire GlaxoSmithKline), Gaëlle Gernigon (DGS, Paris) Chrystel Jouan-Flahault (Leem-Ariis, Paris), Catherine Lassale (Leem-Ariis, Paris), Hervé Le Louet (CRPV, Hôpital Henri Mondor, Paris), Daniel Levy-Bruhl (INVS, Saint-Maurice), François Meyer (HAS, Saint-Denis), Sophie Muller (Laboratoire GlaxoSmithKline), Benoît Soubeyrand (Laboratoire Sanofi Pasteur MSD), Bernard Teisseire (CEPS, Ministère de la Santé, Paris).

\section{References}

1. Ministère de la Santé et des Solidarités. Avis du comité technique des vaccinations et du conseil supérieur d'hygiène publique de France relatif à la vaccination contre les papillomavirus humains $6,11,16,18.9$ mars 2007 http://www. sante-sports.gouv.fr/dossiers/cshpf/a mt_090307_papillomavirus.pdf

2. Haut Conseil de la Santé Publique. Avis relatif à la vaccination contre les papillomavirus humains 16 et 18 par un vaccin bivalent. 14 décembre 2007 http://www.hcsp.fr/docspdf/avisrapports/ hcspa20071214_Papillomavirus.pdf

3. Ministère de la Santé et des Solidarités. Avis du conseil supérieur d'hygiène publique de France relatif à la vaccination par le vaccin antipneumococcique conjugué chez les enfants de moins de deux ans et les enfants de deux à cinq ans. 19 mai 2006 http://www. sante.gouv.fr/ htm/dossiers/cshpf/a_mt_190506_pneumo_enf.pdf

4. Haut Conseil de la Santé Publique. Avis relatif à la vaccination par le vaccin méningoccique conjugué de sérogroupe conjugué. 24 avril et 26 juin 2009 http://www.hcsp.fr/explore.cgi/avisrapportsdomaine? ae=avi srapportsdomaine\&clefdomaine $=1 \&$ menu $=09$

5. Leem. 50 questions sur les vaccins. http://www.leem-media.com/ leem/Communiques/Dossiers-de-presse/Innovation-RechercheProgres-therapeutique-Vaccins/Les-vaccins-bouclier-de-1avenir

6. Ministère de la Santé et des Sports. Calendrier vaccinal détaillé 2009. http://www . sante-sports .gouv. fr/calendrier-vaccinaldetaille-2009.html 
7. EMEA European Public Assessment Reports Zostavax ${ }^{\circledR}$ http://www . ema. europa.eu/humandocs/Humans/EPAR/zostavax/zostavax.htm

8. EMEA European Public Assessment Reports Rotateq ${ }^{\circledR}$. http://www.ema . europa. eu/humandocs/Humans/EPAR/rotateq/rotateq.htm

9. EMEA European Public Assessment Reports Prevenar ${ }^{\circledR}$. http://www .ema . europa.eu/humandocs/Humans/EPAR/prevenar/prevenar.htm

10. Afssaps. Plans de gestion des risques Gardasil et Cervarix ${ }^{\circledR}$. http: //www . afssaps.fr/Activites/Plans-de-gestion-des-risques

11. Haute Autorité de Santé. Avis de la Commission de la Transparence Gardasil du 18 avril 2007. http://www.has-sante.fr/portail/jcms/ c_523363/gardasil

12. Kaiser Permanente. http://xnet.kp.org/clinicaltrials/

13. United States Department of Veterans Affairs. http://www.va.gov

14. Julius Center. Clinical Trial Monitoring. http://www.juliuscentrum. nl/julius/Services/ClinicalTrialMonitoring/tabid/861/ Default.aspx.

15. General Practices Research Database (GPRD). http://www.gprd.com

16. Assurance Maladie. Données statistiques. http://www.ameli.fr/l-assurancemaladie/statistiques-et-publications/donnees-statistiques/index.php

17. ATIH. http://www.atih.sante.fr

18. Bonmarin I, Santa-Olalla P, Bernillon P, et al. Modélisation de l'impact de la vaccination sur l'épidémiologie de la varicelle et du zona. Août 2008. http://www.invs.sante.fr/recherche/index2.asp? txtQuery=varicelle+zona

19. Roadmap française des très grandes infrastructures de recherche (TGIR). 9 décembre 2008 http: //www . roadmaptgi .fr/

20. ARIIS. Symposium Leem Recherche INCa sur la recherche translationnelle en cancérologie. http://www.leem-recherche.org/ 8/335-symposium-leem-recherche-inca-sur-la-recherchetranslationnelle-en-cancerologie-presentations-en-ligne/

21. Ministère de la Santé, de la Jeunesse et des Sports. Arrêté du 18 septembre 2007 relatif au Comité technique des vaccinations. http://textes. droit.org/JORF/2007/09/27/0224/0027/
22. InVS. La modélisation mathématique : un outil d'aide à la décision en situation d'incertitude. Novembre 2008 http ://www . invs . sante. fr/recherche/index2 . asp? txtQuery=mod\%E9lisation+math\%E9matique

23. République française. Article L. 3111-1 de la Loi du 4 août 2004 du Code de la Santé Publique. http://www.legifrance.gouv.fr/html/actualite/ actualite_legislative/decrets_application/2004-806.htm

24. Haute Autorité de Santé (HAS). Nouvelle organisation des Commissions de la HAS. Communiqué de presse. 4 juillet 2008. http://www.hassante.fr/portail/jcms/c_676358/nouvelle-organisation-descommissions-de-la-has

25. Plotkin SL, Plotkin SA. Chapter one. In: Plotkin and Orenstein. Vaccines 2008

26. INPES. Baromètre pharmaciens/medecins 2003. http://www . inpes . sante. $\mathrm{fr} /$ index . asp?page=CFESBases/catalogue/ detailspecial . asp?numfiche $=793 \&$ order=undefined

27. INPES. Baromètre santé 2005 http://www.inpes.sante.fr/ index . asp ?page $=$ CFESBases $/$ catalogue/detailspecial . asp? numfiche $=1109$ \&order $=$ undefined

28. Davies P, Chapman S, Leask J. Antivaccination activists on the world wide web. Arch Dis Child 2002 Jul; 87(1): 22-5

29. Wolfe RM. Vaccine safety activists on the Internet. Expert Rev Vaccines 2002 Oct; 1(3): 249-52

30. http://www.infovac.fr

Correspondence and offprints: Odile Launay, Université Paris Descartes, AP-HP, Inserm, CIC de Vaccinologie Cochin Pasteur, 27 rue du Faubourg Saint-Jacques, 75679 Paris Cedex 14, France.

E-mail: odile.launay@cch.aphp.fr 